\title{
A Collective Education Mentorship Model (CEMM): Responding to the TRC Calls to Action in Undergraduate Indigenous Health Teaching
}

Sharon Yeung, School of Medicine, Queen's University, Canada Yipeng Ge, Faculty of Medicine, University of Ottawa, Canada Deepti Shanbhag, School of Medicine, Wayne State University, United States Alexandra Liu, Faculty of Medicine, University of Toronto, Canada Bernice Downey, School of Nursing, McMaster University, Canada Karen Hill, Juddah's Place, Six Nations of the Grand River, Canada Dawn Martin-Hill, Indigenous Studies Program, McMaster University, Canada Ellen Amster, Departments of Family Medicine and Religious Studies, McMaster University, Canada

Constance McKnight, De dwa da dehs nye>s Aboriginal Health Centre, Canada Gita Wahi, Department of Pediatrics, McMaster University, Canada

Contact: 15shyy@queensu.ca

\section{ABSTRACT}

In this paper, a Collective Education Mentorship Model (CEMM) is described by four non-Indigenous students who co-created and undertook a program with this model for an undergraduate-level university experiential learning experience centred around Indigenous health. This model is framed around shared teaching of students by various collaborators/mentors and built upon the values of collaboration, mentorship, reciprocity, and capacity building. Based on feedback from the students and collaborators involved in this experience, this model appears to be a promising means of better situating students as partners in experiential learning through the redefinition of student-supervisor roles, responsibilities, and the sharing of power. Furthermore, this model appeared to create more diverse experiences for students and minimized supervisor burden. Although this model was created specifically for the education of trainees in Indigenous health, it can be further adapted for other student placements and programs where these assets would be beneficial.

\section{KEYWORDS} mentorship, undergraduate, experiential, Indigenous health, community engagement 
Multi-mentoring, team-based mentoring, and community mentoring are models that have been utilized in the past in the context of undergraduate-level university research (Huizing 2012; Nicholson et al., 2017; Young et al., 2015; de Janasz, \& Sullivan, 2004; Sorcinelli \& Yun,, 2007). The many-to-many model of mentoring (in which multiple mentors interact with multiple mentees) is a cited structure with documented professional and personal development benefits that has been critical to challenging the traditional one-on-one apprenticeship model within undergraduate education (Girves et al., 2005; de Janasz \& Sullivan, 2004). These models have evolved due to the increasingly complex environment of academia, and in order to be inclusive of underrepresented groups (Nicholson et al., 2017; de Janasz \& Sullivan, 2004; Sorcinelli \& Yun, 2007). Furthermore, these models have been found to accommodate limitations in mentor skills, time, and financial resources, as well as facilitate an environment that promotes interdependence, mutuality, and reciprocity, which better situate students as partners in mentorship relationships (de Janasz \& Sullivan, 2004). In shared mentorship models, students are exposed to a greater variety of ideas and information, as mentors bring different strengths and fulfill different gaps. Despite the applicability of these models to experiential learning in Indigenous health, such experiences have not yet been documented.

In 2015, the Truth and Reconciliation Commission (TRC) of Canada published 96 Calls to Action to advance the process of reconciliation in Canada. Three of these Calls to Action identified the importance of education for building student capacity for intercultural understanding, empathy, and mutual respect (Truth and Reconciliation Commission of Canada, 2015). In conjunction with this, student interest in the history, culture, and health of Indigenous peoples in Canada has increased, particularly at the post-secondary level (Yeung et al., 2018). These recent developments have posed new challenges for educators, as there is a general shortage of Indigenous mentors and teachers in post-secondary institutions (Henry, 2012). The increase in demand for their teaching and supervision, particularly for work and experiential education placements, research positions, and graduate theses has led to a heavy "supervisor burden" that has made it difficult for these teachers to balance student mentorship with other academic responsibilities. A related issue pertains to the importance of prioritizing mentorship by Indigenous mentors for Indigenous trainees, as greater positive impact has been identified when mentors and mentees can relate more personally and identify similarly (Rose, 2005; Garvey et al., 2009; Mangan \& Trendle, 2019). Enabling these relationships to be constructed meaningfully in academia also requires that Indigenous mentors and teachers are not inundated by other mentorship demands.

This article intends to outline and propose the use of a shared mentorship model for the teaching of Indigenous health trainees to combat disproportionate burdens associated with supervisorship. Furthermore, we argue that the values imbued in shared mentorship can be more aligned with the philosophy of Students as Partners, and ultimately, more suited to learning experiences in Indigenous health.

\section{HISTORY AND CONTEXT}

The Collective Education Mentorship Model (CEMM) was developed in 2015 at McMaster University in Hamilton, Ontario, Canada by Dr. Bernice Downey, the current 
Indigenous Health Lead at the Faculty of Health Sciences, and a group of four students in the Bachelor of Health Sciences (BHSc) Honours Program. This program offers an interdisciplinary approach to the study of health and disease and emphasizes the Inquiry model of learning, which applies problem-based, self-directed learning in collaborative, small-group settings (Ai et al., 2008; McMaster University Bachelor of Health Sciences Honours Program, 2018). The CEMM was created for the Extended Learning Experience (ELE), an experiential learning course offered to students in the global health specialization of the BHSc program. ${ }^{1}$

The CEMM was designed unintentionally as a result of the student group's difficulties with finding a primary supervisor willing to oversee four students over a semester-long experiential learning opportunity. Discussions with Dr. Bernice Downey, the eventual main student advisor, drew their attention to the reality of supervisor burden that made the supervisorship of four full-time students very infeasible. Through these conversations, Dr. Downey agreed to assume the role of a "navigator" for the students, helping them develop relationships with various Indigenous collaborators. Her expertise, personal experiences, and unique position as both a recent doctorate student and transitioning member of faculty led her to craft the vision for the CEMM as one that would uniquely position students and collaborators as partners in a reciprocal learning relationship.

\section{IMPLEMENTATION AND STRUCTURE}

The CEMM was a student-designed model of shared mentorship, wherein a small group of students received teaching from multiple collaborators simultaneously throughout the duration of their learning placement. This model adopted a specific language: the term "collaborator" was used instead of "supervisor" or "teacher" (as in traditional student placements) in order to distinguish the CEMM as a model that promotes greater student participation and involvement in the experiential learning partnership. This language was also more inclusive of the diverse identities of participating individuals: while the traditional language of "supervisor" or "teacher" largely alludes to those in academe, the use of "collaborator" welcomed a greater diversity of participants, including faculty members, local community organizers, and other knowledge holders of students' choice.

In the operationalization of this model, students worked on multiple different projects with their various collaborators simultaneously and collectively participated in diverse experiences and opportunities offered by collaborators. The model was also called a mentorship model because it was intended to go above and beyond simply teaching of students; it was aimed to promote the guidance of students, both in their journeys of learning, but also in their careers, their worldviews, and through role modeling.

In the first application of the CEMM, shared mentorship of four students was undertaken by six collaborators. The initial outreach for collaborators was challenging, as students found that they lacked connections with the local Indigenous communities. Eventually, through their broad outreach, the group connected with Dr. Bernice Downey, who agreed to assume the role as the "navigator" throughout this experience. As an Indigenous postdoctorate student, Dr. Downey was instrumental in bridging the gap between the students and the Indigenous communities. She assisted in the development of relationships between the

Yeung, S., Ge, Y., Shanbhaa, D., Liu, A., Downey, B., Hill, K., Martin-Hill, D., Amster, E., McKnight, C., 140 \& Wah, G. (2020). A collective education mentorship model (CEMM): Responding to the TRC calls to action in undergraduate Indigenous health teaching. International Journal for Students as Partners, 4(1). https://doi.org/10.15173/ijsap.v4i1.3878 
students and the collaborators she recruited, keeping both parties responsible to a relationship of reciprocity that would be beneficial to both students and collaborators. The process of brokering relationships took approximately one month and involved preliminary meetings with collaborators and attending community gatherings, events, and other informal activities. Once participation was confirmed from all parties, each collaborator was appointed one specific student, who would act as the main liaison between the collaborator and the group. Ultimately, a diverse group of collaborators and projects was assembled, spanning fields such as anthropology, history of medicine, public health, and pediatrics.

The experiential learning experience framed around the CEMM was by nature one that was relational: the group of students met with each collaborator individually, as well as collectively. The initial meetings between the group and individual collaborators were used to explain the logistics of the CEMM and the responsibilities and benefits of participating. Collaborators were also given the opportunity to explain their expectations for the experience, as well as details about any deliverables they were hoping the group could produce. At the end of the CEMM experience, one collective meeting was also held with all collaborators, students, program advisors, and interested faculty. This final, collective meeting was used for students to present their learnings from the experience as a whole, many of which were drawn from working across disciplines and through many projects. This collective meeting also allowed collaborators to interact with one another and actively participate in the social network created through the students. The original design of the model intentioned more of these collective meetings to be held, including one at the beginning and halfway through the experience. Given the inaugural nature of this experience, it was logistically challenging to organize more than one meeting, but multiple meetings should be intentioned in future implementations of the CEMM.

\section{Figure 1: Comparison of the traditional research supervisorship model with the CEMM}

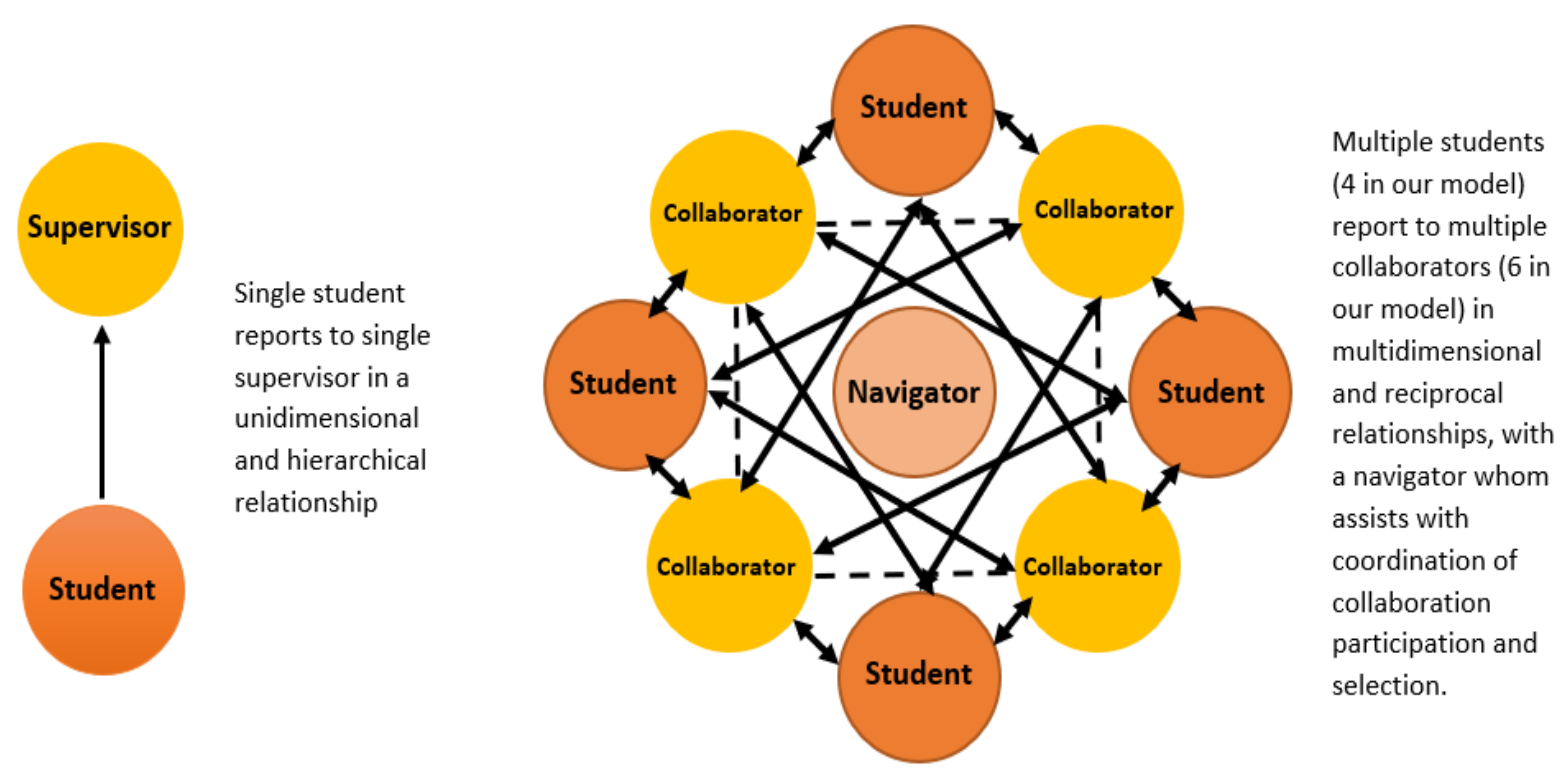

Yeung, S., Ge, Y., Shanbhaa, D., Liu, A., Downey, B., Hill, K., Martin-Hill, D., Amster, E., McKnight, C., 141 \& Wah, G. (2020). A collective education mentorship model (CEMM): Responding to the TRC calls to action in undergraduate Indigenous health teaching. International Journal for Students as Partners, 4(1). https://doi.org/10.15173/ijsap.v4i1.3878 


\section{SUCCESSES AND CHALLENGES}

\section{Successes}

From the students' perspective, the CEMM provided a versatility of experiences that would not exist in the scope of a traditional one-on-one student supervisorship. Throughout this experience, the students assumed hybrid identities: they were at once project partners, but also observers, personal assistants, and mentees. As such, the experiences they underwent were diverse, including the traditional academic activities of giving research presentations and preparing posters, as well as non-academic experiences, such as shadowing board meetings and attending community events. These non-academic experiences exposed students to the understanding of complexities faced by Indigenous collaborators within institutions and gave them authentic perspectives on historical and ongoing racial tensions. This wide range of mentorship broadened students' understandings of the multidisciplinary skills and tools critical to work effectively and appropriately in Indigenous health. This flexibility also enabled students to direct the recruitment of collaborators from different stages of their careers, allowing students to also receive many different insights on personal career development and trajectory.

The CEMM also increased the flexibility and autonomy students had with their learning experience. Without the obligation and logistical setup of a traditional full-time placement, students were able to choose how many, as well as which projects they wanted to be involved in. Ultimately, students were more authentically positioned as partners with collaborators in that the distribution of power was more equitable: in contrast to traditional experiential learning experiences, in which a supervisor "hires" a student, it was the students who were empowered to add projects and collaborators as they saw fit with the guidance and mentorship of their navigator, based on specific areas or topics of interest to the group.

\section{Challenges}

The CEMM involved multiple different collaborators, each of whom expressed different levels of interest in the model. While some collaborators were very interested in participating in the network of Indigenous health professionals the model intended to create, others were more singularly interested in the relationship with the students. Several others had primary interest in the ability of students to contribute to their projects. As a result, the dynamics of the relationship between the group and each collaborator varied considerably and balancing and navigating these complex relationships simultaneously was challenging for the students. The large number of collaborators and faculty overseers involved in this model also posed a challenge to scheduling large group gatherings or meetings, and several collaborators were ultimately unable to attend the meeting hosted at the end of the CEMM.

This experience was also limited in its length as a semester-long commitment. Given that implementing the CEMM required a significant amount of time to organize logistically, particularly the process of collaborator recruitment, the actual experience itself only effectively lasted three months. The long-term, slow-progressing nature of many Indigenous health projects was thus challenging for students to contribute to within this timeframe, and students made less progress on their work than they had initially hoped. In the future, it is recommended that this model be adopted for longer student placements (or in an ongoing 
longitudinal manner), in order that both students and collaborators receive maximal benefit from the logistical cost of organizing the experience.

\section{THEMES OF THE MODEL}

The CEMM was built upon key themes that are particularly relevant to teaching and training in Indigenous health in a post-TRC Calls to Action environment. These themes are also resonant with those that have been cited in Students-as-Partners literature, aligning with concepts of reciprocity; realities of partnership outcomes; context of practices; and inclusive, partnered learning with communities (Mercer-Mapstone et al., 2017).

First, the CEMM was built upon collaboration and reciprocity-among students, between students and collaborators, and among collaborators themselves. Each of the collaborators possessed different fields of expertise, and student exposure to these different perspectives taught them about the interdisciplinary nature of Indigenous health work and research. The creation of a network among collaborators also enforced the theme of working together within Indigenous health and exemplified the capacity for students, in their role as partners, to bring together those working in the same field.

Second, the CEMM prioritized mentorship of students. This was facilitated by the stipulation that none of the collaborators would be responsible for assigning grades directly to the students. As a result, the pressure frequently placed on individuals in the supervisory position to grade students, and the pressure placed on students to impress their supervisors, was reduced overall. The power imbalance was reduced, and students were more authentically able to become partners in the learning relationship, without the constant pressure of evaluation. This facilitated more organic learning and relationship building - students were permitted to, at times, simply sit aside to observe collaborators' approaches to managing a project, or shadow collaborators' daily activities, for example, without the worry of not constantly producing tangible contributions for student evaluation purposes.

Given that students were established as partners in the mentorship relationship with collaborators, the value of reciprocity was also of great importance. While students were welcome to come aboard to learn from their collaborators through informal ways, formal learning and assignment of specific projects and tasks was also necessary for the collaborators to benefit from the partnership. In the CEMM, the notion of reciprocal relationships was regularly considered in the design of student-led activities. For example, through the CEMM, the students worked to facilitate collaborator networking, which was intended to include collaborators as beneficiaries in the student-collaborator relationship and to establish students as partners capable of making tangible and unique contributions. Increasing the ability for collaborators to benefit from this learning and teaching model continues to be an area of development.

Finally, the CEMM was designed with the goal of capacity building and the formation of future partnerships between students and collaborators. The CEMM enabled students to learn from collaborators, who provided personal mentorship, as well as the opportunity to work on specific projects, which built capacity in students' academic skills. The establishment of these

Yeung, S., Ge, Y., Shanbhaa, D., Liu, A., Downey, B., Hill, K., Martin-Hill, D., Amster, E., McKnight, C., 143 \& Wah, G. (2020). A collective education mentorship model (CEMM): Responding to the TRC calls to action in undergraduate Indigenous health teaching. International Journal for Students as Partners, 4(1). https://doi.org/10.15173/ijsap.v4i1.3878 
partnerships between students and their collaborators in this experience also hoped to set a precedent for future partnerships between Indigenous community members and students. In particular, non-traditional mentorship models may benefit Indigenous trainees substantially by helping to facilitate continued development of capacity and equitable representation. Through the CEMM experience, all four students gained additional appreciation and respect for the notion and importance of allyship in Indigenous health work and for collective reconciliation efforts and principles by the nature of the work they were doing, but also through the values the CEMM itself espoused.

\section{IMPLICATIONS AND CONCLUSION}

The CEMM represented a model of experiential learning that challenged the role of students as passive, primary beneficiaries of learning experiences, and instead placed them in the centre of reciprocal student-collaborator relationships founded on a principle of equal partnership and learning from one another. Through its emphasis on balancing learner, collaborator, and community needs and the creation of equitable benefits for all parties involved in an experiential learning experience, this model was appropriately suited for Indigenous health training and directly addressed the TRC's Calls to Action that call into question the importance of education for building student capacity for intercultural understanding, empathy, and mutual respect (Truth and Reconciliation Commission of Canada, 2015). The CEMM also acknowledged and attempted to address the heavy supervisor burden facing Indigenous teachers in the academy and community that has accrued over recent years. It should be noted that this model must be ultimately used in conjunction with (and not in place of) further Indigenization of institutional hiring and capacity-building practices. Indigenous university faculty members continue to be under-represented and concentrated in certain disciplines as a result of the inadequate creation of space for Indigenous knowledge holders within institutions (Andersen, et al., 2008; Henry, 2012).

In conclusion, our findings show that shared mentorship models like the CEMM are effective as a means of more authentically situating students as partners in experiential learning activities through an emphasis on student-directed programming with reciprocal and collaborative relations with mentors. It is recommended that the teaching of Indigenous health may specifically benefit from models like the CEMM, given its embedded values of collaboration, reciprocity, mentorship, and capacity-building, all of which are integral to understanding allyship and reconciliation in a post-TRC era.

\section{ACKNOWLEDGMENTS}

Embarking on this educational journey would not have been possible without the guidance, mentorship, and kindness of our collaborators: Dr. Karen Hill, Dr. Dawn Martin-Hill, Dr. Ellen Amster, Ms. Constance McKnight, Dr. Gita Wahi, Dr. Sonia Anand, and Dr. Amber Skye. We are incredibly grateful to Dr. Bernice Downey, whose leadership and vision in assembling this opportunity were instrumental in the development of the CEMM. Finally, we acknowledge the contributions of Dr. P.K. Rangachari and Dr. Delsworth Harnish, Ms. Jennifer Landicho, as 
well as the faculty of the Bachelor of Health Sciences Program, without whom the creation of educational experiences like these would be impossible.

\section{NOTES}

1. Following a year of coursework in the foundations of global health, students in this specialization embark on a self-designed ELE lasting a semester (or more) for the purpose of acquiring direct exposure and experience with global health work. Although the ELE is intended to be an experiential learning experience, it is not a typical experiential learning placement, in that students must look for their own supervisors (should they wish to have any) and are free to select a topic (or multiple topics) of their own interest. Furthermore, students are evaluated by the Assistant Dean of the BHSc program (and not any collaborators or supervisors) and are required to demonstrate evidence of active reflection throughout the experience. The emphasis of this course is on the process of learning, and not the tangible outputs.

\section{NOTE ON CONTRIBUTORS}

Sharon Yeung is a medical student at the Queen's University School of Medicine. She completed her Bachelor's of Health Sciences (Honours) degree with a Global Health Specialization at McMaster University in 2012.

Yipeng Ge is a medical student at the University of Ottawa Faculty of Medicine. He completed his Bachelor's of Health Sciences (Honours) degree with a Global Health Specialization at McMaster University in 2012.

Deepti Shanbhag is a medical student at the Wayne State University School of Medicine. She completed her Bachelor's of Health Sciences (Honours) degree with a Global Health Specialization at McMaster University in 2012.

Alexandra Liu is a medical student at the University of Toronto Faculty of Medicine. She completed her Bachelor's of Health Sciences (Honours) degree with a Global Health Specialization at McMaster University in 2012.

Bernice Downey is Ojibwe/Irish and a medical anthropologist appointed as Assistant Professor to the School of Nursing and the Department of Psychiatry \& Behavioural Neurosciences at McMaster. Dr. Downey is also the Indigenous Health Lead for the Faculty of Health Science and the A/Director for the McMaster Indigenous Research Institute. Her current research interests include Indigenous health, health literacy, and Indigenous Traditional knowledge and health/research system reform for Indigenous populations.

Karen Hill is a Mohawk physician from Six Nations of the Grand River Territory. Dr. Hill's vision is to see Traditional Indigenous Knowledge return to the centre of healthcare for Indigenous people across Canada. This vision led her to co-create a collaborative practice with Traditional 
Medicine Practitioners at Six Nations called "Juddah's Place." Dr. Hill continues to practice family medicine at Six Nations and Moose Factory. She has completed a four-year apprenticeship in Traditional Indigenous Medicine and continues this learning along with Mohawk language classes as lifelong commitments.

Dawn Martin-Hill is an Associate Professor in the Department of Anthropology and CIHR Chair, College of Reviewers. She currently leads two Global Water Futures projects called 'Co-creation of Indigenous water quality tools' and 'Ohneganos: Indigenous Ecological Knowledge'. She is also an investigator on the CIHR Institute of Indigenous Peoples' Health grants entitled 'Tehtsitehwa: kenrotka: we (together we pull it from the earth again)' and 'Akwe:kon tewatahtonokwe (We Are All Related)'.). She also recently held NSERC, Fulbright and SSHRC grants. Indigenous women and community lead all her research within an Indigenous knowledge framework. She has a peer-reviewed book and numerous published articles. She resides at Six Nations of the Grand River.

Ellen Amster is the Hannah Chair in the History of Medicine at McMaster University. She is an interdisciplinary historical scholar of the Islamic world, medicine, France, science, and gender, with interests in scientific modernity in Western and Islamic thought, women's histories, public health, and citizenship.

Constance McKnight, CAE, is the Chief Executive Officer at De dwa da dehs nye ss Aboriginal Health Centre. The Aboriginal Health Centre is an Indigenous-owned and Indigenous-driven Health Centre with core operations in Hamilton and Brantford, and patient navigation and mental health services in the Niagara Region of Ontario.

Gita Wahi is an Associate Professor in the Department of Pediatrics at McMaster University and Pediatrician in the Division of General Pediatrics. Her research interests focus on understanding the determinants of childhood obesity, including the contribution of the early life environment on the risk for childhood obesity and related cardiovascular risk factors among diverse ethnic groups.

\section{REFERENCES}

Ai, R., Bhatt, M., Chevrier, S., Ciccarelli, R., Grady, R., Kumari, V., Li, K., Nazarli, N., Rahimi, H., Roberts, J., Sachs, J., Schepmyer, A., Wang, M., \& Wong, H. (2008). Choose your own inquiry. BHSc (Honours) Program, Faculty of Health Sciences, McMaster University: University Press of America. Retrieved from https://bhsc.mcmaster.ca/about/inquiry/

Andersen, C., Bunda, T., \& Walter, M. (2008). Indigenous higher education: The role of universities in releasing the potential. The Australian Journal of Indigenous Education, 37(1), 1-8. https://doi.org/10.1017/S1326011100016033

de Janasz, S., \& Sullivan, S. (2004). Multiple mentoring in academe: Developing the professorial

Yeung, S., Ge, Y., Shanbhaa, D., Liu, A., Downey, B., Hill, K., Martin-Hill, D., Amster, E., McKnight, C., 146 \& Wah, G. (2020). A collective education mentorship model (CEMM): Responding to the TRC calls to action in undergraduate Indigenous health teaching. International Journal for Students as Partners, 4(1). https://doi.org/10.15173/ijsap.v4i1.3878 
network. Journal of Vocational Behavior, 64(2), 263-283.

https://doi.org/10.1016/j.jvb.2002.07.001

Garvey G, Rolfe IE, Pearson SA, Treloar C. (2009). Indigenous Australian medical students' perceptions of their medical school training. Medical Education, 43(11).

Girves, J., Zepeda, Y., \& Gwathmey, J. (2005). Mentoring in a post-affirmative action world. Journal of Social Issues, 61(3), 449-479. https://doi.org/10.1111/i.15404560.2005.00416.x

Henry, F. (2012). Indigenous faculty at Canadian universities: Their stories. Canadian Ethnic Studies, 44(2), 101-132. https://doi.org/10.1353/ces.2012.0005

Huizing, R. (2012). Mentoring together: A literature review of group mentoring. Mentoring \& Tutoring: Partnership in Learning, 20(1), 27-55. https://doi.org/10.1080/13611267.2012.645599

McMaster University Bachelor of Health Sciences Honours Program. (2018). What is Inquiry? Retrieved from https://bhsc.mcmaster.ca/about/inquiry/

Mercer-Mapstone, L., Dvorakova, S., Matthews, K., Abbot, S., Cheng, B., \& Felten, P., Knorr, K., Marquis, E., Shammas, R., \& Swaim, K. (2017). A systematic literature review of students as partners in higher education. International Journal for Students as Partners, 1(1). https://doi.org/10.15173/ijsap.v1i1.3119

Nicholson, B., Pollock, M., Ketcham, C. J., Fitz Gibbon, H. M., Bradley, E. D., \& Bata, M. (2017). Beyond the mentor-mentee model: A case for multi-mentoring in undergraduate research. PURM Perspectives on Undergraduate Research and Mentoring, 6(1). Retrieved from https://blogs.elon.edu/purm/2017/10/26/beyond-the-mentor-menteemodel-a-case-for-multi-mentoring-in-undergraduate-research-purm-6-1/

Mangan J, Trendle B. (2019). Evaluating the effectiveness of a mentoring program for Indigenous trainees in Australia using propensity score analysis. Education Economics, 27(3), 308-22.

Rose D. (2005). An Indigenous Philosophical Ecology: Situating the Human. Australian Journal of Anthropology, 16(3), 294-305. https://doi.org/10.1111/j.1835-9310.2005.tb00312.x

Sorcinelli, M., \& Yun, J. (2007). From mentor to mentoring networks: Mentoring in the new academy. Change: The Magazine of Higher Learning, 39(6), 58-61. https://doi.org/10.3200/chng.39.6.58-c4

Truth and Reconciliation Commission of Canada. (2015). Truth and Reconciliation Commission of Canada: Calls to action. Retrieved from http://trc.ca/assets/pdf/Calls to Action English2.pdf

Yeung, S., Bombay, A., Walker, C., Denis, J., Martin, D., Sylvestre, P., \& Castleden, H. (2018). Predictors of medical student interest in Indigenous health learning and clinical practice: A Canadian case study. BMC medical education, 18(1), 307. https://doi.org/10.1186/s12909-018-1401-1

Young, B.-R., Williamson, H. J., Burton, D. L., Massey, O. T., Levin, B. L., \& Baldwin, J. A. (2015). Challenges and benefits in designing and implementing a team-based research mentorship experience in translational research. Pedagogy in Health Promotion, 1(4), 233-246. https://doi.org/10.1177/2373379915600174

Yeung, S., Ge, Y., Shanbhaa, D., Liu, A., Downey, B., Hill, K., Martin-Hill, D., Amster, E., McKnight, C., 147 \& Wah, G. (2020). A collective education mentorship model (CEMM): Responding to the TRC calls to action in undergraduate Indigenous health teaching. International Journal for Students as Partners, 4(1). https://doi.org/10.15173/ijsap.v4i1.3878 